Article

\title{
Ribbon $\alpha$-Conotoxin KTM Exhibits Potent Inhibition of Nicotinic Acetylcholine Receptors
}

\author{
Leanna A. Marquart ${ }^{1}$ (D), Matthew W. Turner ${ }^{2}$, Lisa R. Warner ${ }^{1}$, Matthew D. King ${ }^{1}$, \\ James R. Groome ${ }^{3}$ and Owen M. McDougal ${ }^{1, * \mathbb{D}}$ \\ 1 Department of Chemistry and Biochemistry, Boise State University, Boise, ID 83725, USA; \\ leannabrown@u.boisestate.edu (L.A.M.); lisawarner@boisestate.edu (L.R.W.); \\ matthewking990@boisestate.edu (M.D.K.) \\ 2 Biomolecular Sciences PhD Program, Boise State University, Boise, ID 83725, USA; \\ matthewturner1@u.boisestate.edu \\ 3 Department of Biological Sciences, Idaho State University, Pocatello, ID 83209, USA; groojame@isu.edu \\ * Correspondence: owenmcdougal@boisestate.edu; Tel.: +208-426-3964; Fax: +208-426-1311
}

Received: 27 October 2019; Accepted: 25 November 2019; Published: 28 November 2019

check for updates

\begin{abstract}
KTM is a 16 amino acid peptide with the sequence WCCSYPGCYWSSSKWC. Here, we present the nuclear magnetic resonance (NMR) structure and bioactivity of this rationally designed $\alpha$-conotoxin ( $\alpha$-CTx) that demonstrates potent inhibition of rat $\alpha 3 \beta 2$-nicotinic acetylcholine receptors (r $\alpha 3 \beta 2-n A C h R s)$. Two bioassays were used to test the efficacy of KTM. First, a qualitative PC12 cell-based assay confirmed that KTM acts as a nAChR antagonist. Second, bioactivity evaluation by two-electrode voltage clamp electrophysiology was used to measure the inhibition of $\mathrm{r} \alpha 3 \beta 2-\mathrm{nAChRs}$ by KTM $\left(\mathrm{IC}_{50}=0.19 \pm 0.02 \mathrm{nM}\right)$, and inhibition of the same $\mathrm{nAChR}$ isoform by $\alpha$-CTx MII $\left(\mathrm{IC}_{50}=0.35 \pm 0.8 \mathrm{nM}\right)$. The three-dimensional structure of KTM was determined by NMR spectroscopy, and the final set of 20 structures derived from 32 distance restraints, four dihedral angle constraints, and two disulfide bond constraints overlapped with a mean global backbone root-mean-square deviation (RMSD) of $1.7 \pm 0.5 \AA$. The structure of KTM did not adopt the disulfide fold of $\alpha$-CTx MII for which it was designed, but instead adopted a flexible ribbon backbone and disulfide connectivity of $\mathrm{C} 2-\mathrm{C} 16$ and $\mathrm{C} 3-\mathrm{C} 8$ with an estimated $12.5 \% \alpha$-helical content. In contrast, $\alpha$-CTx MII, which has a native fold of C2-C8 and C3-C16, has an estimated $38.1 \% \alpha$-helical secondary structure. KTM is the first reported instance of a Framework I (CC-C-C) $\alpha-C T x$ with ribbon connectivity to display sub-nanomolar inhibitory potency of $\mathrm{r} \alpha 3 \beta 2-\mathrm{nAChR}$ subtypes.
\end{abstract}

Keywords: $\alpha$-conotoxin; nicotinic acetylcholine receptor; NMR; two-electrode voltage clamp electrophysiology; PC12 cell; DockoMatic

\section{Introduction}

Conotoxins are 10-50 amino acid peptide toxins present in the venom of predatory marine snails of the genus Conus. With sequence hypervariability and disulfide bond constrained scaffolds, conotoxins have a complex classification system of 28 superfamilies, segregated in part by activity on ion channels present in excitable tissues such as nerve and muscle [1]. $\alpha$-Conotoxins ( $\alpha$-CTxs) target ligand-gated nicotinic acetylcholine receptor ( $\mathrm{nAChR}$ ) ion channels and inhibit ion flow by causing a dynamic structural change upon binding that results in the closing of the channel. nAChRs are pentameric transmembrane channel proteins that form different combinations of homo and heteropentameric subtypes, leading to a range of functions and ligand specificity across the host. nAChRs are found in many tissues including muscle and the central and peripheral nervous systems, and perform numerous physiological functions, such as the modulation of neurotransmitter release in the central nervous system 
by post and presynaptic excitation [2]. In the modulation of neurotransmitter release, acetylcholine activation of presynaptic nAChRs causes sodium influx and subsequent cellular depolarization, resulting in the activation of voltage-gated calcium channels and an influx of calcium ions that initiates a signaling cascade ending in the release of dopamine-containing vesicles. Because of their involvement in neurotransmitter release, nAChRs play a central role in the pathology of Parkinson's disease and other neurological disorders. For example, Parkinson's disease patients experience a degradation of neurons expressing $\alpha 6 \alpha 4 \beta 2 \beta 3-n A C h R s$ and consequently display symptoms reflecting loss of function dependent on dopamine release. Targeting specific nAChR isoforms is a promising strategy in the development of improved drug therapies for Parkinson's disease and other neurological diseases, including Alzheimer's, Tourette's, and Schizophrenia [3-7]. However, there still exists a gap in understanding of the mechanism of $\mathrm{nAChR}$-ligand binding.

$\alpha$-CTxs possess rigid scaffolds and are among the most potent inhibitors of nAChRs, making them insightful molecular probes for the elucidation $\mathrm{nAChR}$ binding paradigms. $\alpha$-CTx structure-activity relationships have been developed for $\alpha$-CTxs and their analogs, leading to the discovery of disease-relevant $\mathrm{nAChR}$ subtypes and the identification of new ligand-nAChR binding sites [8-10]. Model systems used to study nAChR-ligand binding include pheochromocytoma (PC12) cell assay [11], electrophysiology [12], mouse brain studies [13-15], and computational molecular dynamics simulations [9,16-27]. Expression systems for studying nAChRs in vitro often prove costly and complex [28-31], highlighting the potential value of computational studies. Emerging computational strategies can produce promising results for $\mathrm{nAChR}$ ligands, but potential small molecule drugs require evaluation by functional experimentation. Here, we present the validation results of a computational study that used the genetic algorithm managed peptide mutant screening (GAMPMS) program in DockoMatic v. 2.1 to predict the sequence for an $\alpha$-CTx MII analog for optimal binding to the rat (r) $\alpha 3 \beta 2$ nAChR isoform; the outcome of the computational study was the designed peptide KTM [16-18].

DockoMatic is an open source program with an intuitive user interface to run software applications for ligand and receptor structure file creation, perform high throughput virtual screening, and output docking results ranked in order from best to worst binding affinity [19-21,32-34]. DockoMatic uses the highly innovative GAMPMS algorithm specifically designed for peptide library creation, and can correlate peptide structure to drug identity by way of the small-molecule peptide-influenced drug repurposing (SPIDR) utility that permits screening of molecular databases using a template structure derived from a peptide scaffold [16-18]. Previously, the GAMPMS algorithm was used to evaluate the binding affinity of over 41 billion combinations of $\alpha$-CTx MII mutants for a homology model of the $\mathrm{r} \alpha 3 \beta 2 \mathrm{nAChR}$ isoform [17]. $\alpha$-CTx MII was selected as a template for this study because it has been well characterized as a very potent and selective inhibitor of the $\mathrm{r} \alpha 3 \beta 2 \mathrm{nAChR}$ isoform. $\alpha$-CTx MII is a 16 amino acid peptide with the primary sequence GCCSNPVCHLEHSNLC and disulfide bonds between C2-C8 and C3-C16. The globular structure of $\alpha$-CTx MII is characterized by an $\alpha$-helix initiated at P6 and ending at H12, providing the peptide with approximately $40 \% \alpha$-helical content. The GAMPMS program was used to change the primary sequence of $\alpha$-CTx MII to create a peptide library of nearly 41 billion unique $\alpha$-CTxs [17]. All amino acids were varied in the primary sequence with the exception of the four cysteine residues required to form disulfide bonds, and the conserved proline at position 6 required for initiation of the $\alpha$-helix. Molecular docking in DockoMatic ranked the peptides by highest binding affinity for the $\mathrm{r} \alpha 3 \beta 2 \mathrm{nAChR}$ isoform. The top fifty mutant peptides with highest affinity for the receptor were compared for amino acid identity at each site in the peptide primary sequence to generate a consensus peptide. Figure $1 \mathrm{~A}, \mathrm{~B}$ shows the sequence and disulfide connectivity of KTM (A), and the sequence comparison of KTM to $\alpha$-CTx MII (B). The consensus peptide, given the arbitrary name KTM (Figure 1A; dashed), represents a rationally designed peptide ligand that was computationally predicted to have enhanced binding affinity for the $\mathrm{r} \alpha 3 \beta 2 \mathrm{nAChR}$ isoform. 


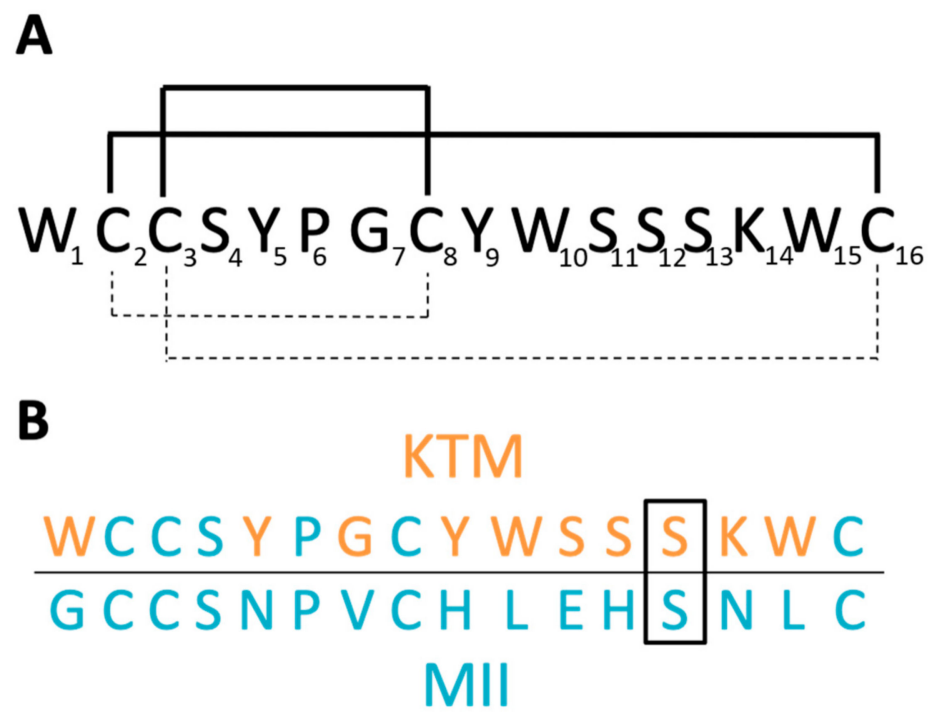

Figure 1. (A) Sequence of KTM with globular disulfide bond connectivity of C2-C8 and C3-C16 (dashed line), and disulfide bonding from oxidative folding following solid phase peptide synthesis of ribbon connectivity C2-C16 and C3-C8 (solid line). (B) Sequence comparison of KTM to $\alpha$-CTx MII. Of the 10 residues in $\alpha$-CTx MII that were allowed to vary in the genetic algorithm managed peptide mutant screening (GAMPMS) algorithm (orange), all but one amino acid (S13, boxed) changed to give the sequence of KTM.

The sequences of $\alpha$-CTx MII and KTM both contain 16 amino acids (Figure 1B). $\alpha$-CTx MII has a Framework I cysteine pattern of CC-C-C, consisting of two disulfide bonds between C2-C8 and C3-C16, making it a globular connectivity pattern, and a $4 / 7$ loop sequence common to many $\alpha$-CTxs [35]. The design of KTM was inspired by the pharmacological features present in $\alpha$-CTx MII and was anticipated to adopt the same globular disulfide connectivity. KTM activity on nAChRs was assessed qualitatively by an in vitro cell-based PC12 luminescence assay, and quantitatively for inhibition of $\mathrm{r} \alpha 3 \beta 2 \mathrm{nAChR}$ isoforms using two-electrode voltage clamp electrophysiology. KTM demonstrates remarkable sub-nanomolar inhibition of selective $n A C h R$ subtypes, commensurate with that of $\alpha$-CTx MII. In the present study, we show that synthetic KTM produced by undirected folding preferentially forms ribbon $\mathrm{C} 2-\mathrm{C} 16$ and $\mathrm{C} 3-\mathrm{C} 8$ disulfide linkages. In their review, Akondi, et al. suggest that correct folding of synthetic peptides is critical to the maintenance of biological activity [35], but in the case of KTM, the globular disulfide pattern is not the same as that found in $\alpha$-CTx MII, but rather resembles that of the ribbon isomer of $\alpha$-CTx AuIB [36,37]. The net effect of the disulfide connectivity is that $\alpha$-CTx MII adopts a globular scaffold, while KTM is consistent with ribbon-connectivity. Solution nuclear magnetic resonance (NMR) spectroscopy was used to determine the three dimensional structure of the synthesized KTM for comparison to $\alpha$-CTx MII and the computationally predicted structure. Molecular dynamics simulations in Gromacs were used to assess peptide dynamics.

\section{Results}

\subsection{Bioactivity}

KTM was qualitatively evaluated for nAChR bioactivity using a PC12 cell assay; antagonist activity by KTM in the presence of acetylcholine (ACh) was confirmed (Figure 2), prompting quantitative evaluation of bioactivity by electrophysiology. In the preliminary screening qualitative assay, $\mathrm{ACh}$ is used to stimulate PC12 cells, opening nAChR channels, resulting in dopamine release [38,39]. Following release, dopamine is oxidized by monoamine oxidase, generating hydrogen peroxide that catalyzes a chemiluminescence reaction involving luminol and horseradish peroxidase, producing a detectable response. Incubation with $\alpha$-CTxs prior to stimulation with ACh inhibits nAChRs, resulting 
in a diminished signal, as is observed for treatment with $\alpha$-CTx MII (see Figure 2). A decreased signal resulting from treatment with KTM indicates that nAChRs are inhibited by this compound.

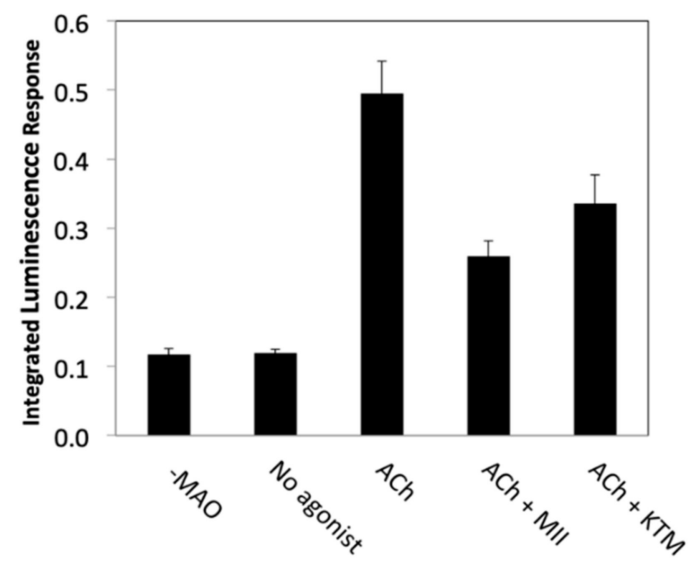

Figure 2. Qualitative PC12 assay luminescence responses upon stimulation of nicotinic acetylcholine receptors (nAChRs) with acetylcholine (ACh), with and without $10 \mu \mathrm{M}$ toxin. Assays performed with the addition of $\alpha$-CTx MII and KTM resulted in a diminished luminescence recording compared to an ACh control.

Two-electrode voltage clamp experiments were used to determine the $\mathrm{IC}_{50}$ for $\mathrm{KTM}$ on $\mathrm{r} \alpha 3 \beta 2$ nAChRs expressed in Xenopus laevis oocytes. Figure 3A shows responses to local application of ACh prior to (left) and following (right) toxin exposure. The concentration-dependent curves for inhibition of $\mathrm{r} \alpha 3 \beta 2 \mathrm{nAChR}$ by MII and KTM are shown in Figure 3B. KTM exhibited potent inhibition with an $\mathrm{IC}_{50}$ of $0.19 \pm 0.02 \mathrm{nM}$ commensurate with $\alpha-\mathrm{CTx}$ MII with an $\mathrm{IC}_{50}$ of $0.35 \pm 0.08 \mathrm{nM}$. $\alpha$-CTx MII and KTM have Hill coefficients of 0.5 and 0.7 , respectively.

A

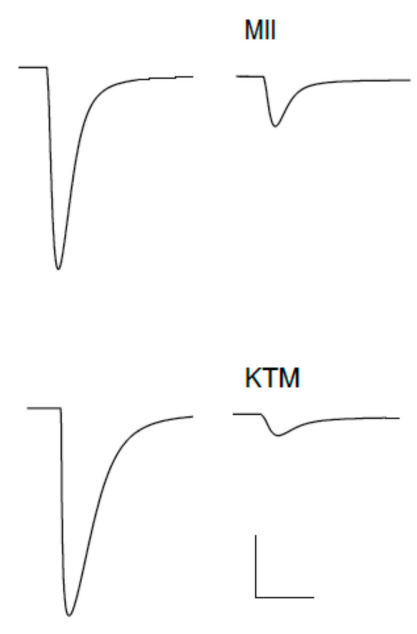

B

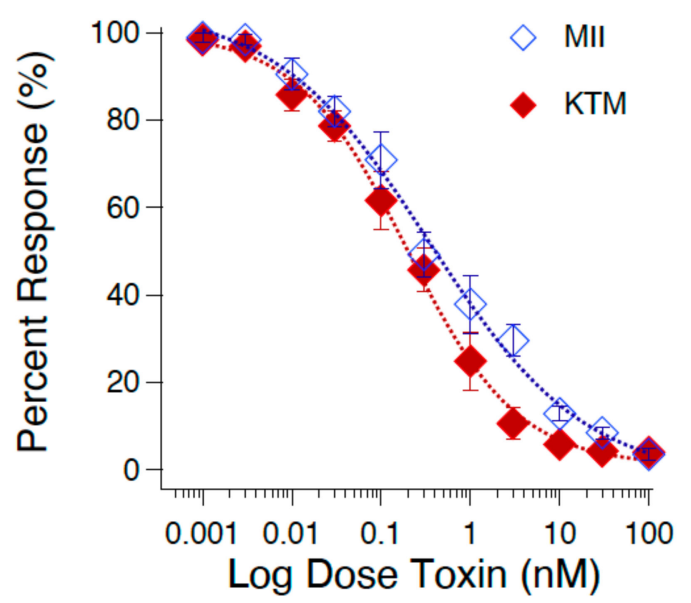

Figure 3. Responses to the local application of ACh for $30 \mathrm{~ms}$ are shown for control and after $3 \mathrm{nM}$ toxin application; calibration horizontal $2 \mathrm{sec}$, vertical $1 \mu \mathrm{A}(\mathrm{A})$. Concentration-dependent response curves for blocking r $\alpha 3 \beta 2 \mathrm{nAChR}$ by $\alpha$-CTx MII (red) and KTM (blue) (B). Hill coefficients for the concentration response curves of $\alpha$-CTx MII and KTM are 0.5 and 0.7 , respectively. IC $_{50}$ values of KTM and $\alpha$-CTx MII are $0.19 \pm 0.02 \mathrm{nM}$ and $0.35 \pm 0.08 \mathrm{nM}$, respectively. Data are means \pm SEM from eight to 12 trials. 


\subsection{Structure Determination}

Analysis of the circular dichroism (CD) spectrum for KTM (Figure 4, double lined grey) gave a predicted $\alpha$-helical content of $12.5 \%$, consistent with the ribbon-type isomer fold (C1-C4; $\mathrm{C} 2-\mathrm{C} 3)$, and not the expected globular-type fold (C1-C3; C2-C4) characteristic of $\alpha-\mathrm{CTx}$ MII, for which the $\alpha$-helical content is $38.1 \%$ (Figure 4 , solid black line). The large negative peak commonly observed for $\alpha$-CTxs corresponds to the $\alpha$-helical portion of the peptide, and is predominantly absent in the CD spectrum of KTM. The interpretation of CD spectra for flexible small peptides is representative of an ensemble of conformations, so it is difficult to draw definitive secondary structure conclusions based solely on CD data. The CD data in Figure 4 did identify variation in the secondary structure between KTM and $\alpha$-CTx MII that brought into question the disulfide connectivity in KTM, necessitating framework determination for KTM by partial reduction mass spectrometry.

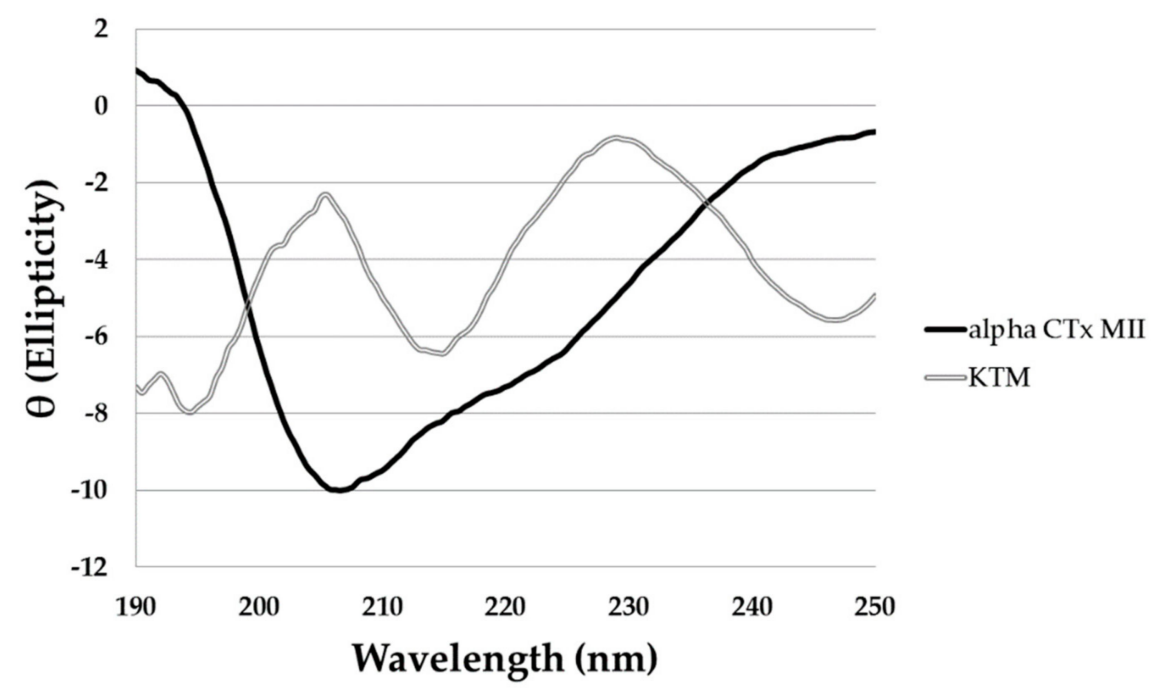

Figure 4. The circular dichroism (CD) spectrum of $\alpha$-CTx MII (solid black line) and KTM (double lined grey). Measurements for each peptide were taken in water at $50 \mu \mathrm{M}$, and a pathlength of $1 \mathrm{~mm}$. The $\alpha$-helical content of $\alpha$-CTx MII and KTM were estimated to be $38.1 \%$ and $12.5 \%$, respectively, as calculated from the observed signal at $222 \mathrm{~nm}$.

Partial reduction by TCEP of 100 pmol of synthetic KTM peptide gave expected product profiles in LC-MS chromatograms with mass increases corresponding to partial reduction $(+2 \mathrm{~m} / \mathrm{z})$ and alkylation (NEM, $+125 \mathrm{~m} / \mathrm{z} ;$ IAA,$+59 \mathrm{~m} / \mathrm{z}$ ) (see Materials and Methods). Sequence analysis showed the disulfide bridging pattern was not consistent with the expected $\alpha-\mathrm{CTx} C 2-\mathrm{C} 8 / \mathrm{C} 3-\mathrm{C} 16$ globular linkage as found in $\alpha$-CTx MII, but rather a C2-C16/C3-C8 ribbon linkage (Figure S1), as observed in $\alpha$-CTx AuIB [36,37].

NMR structure determination for KTM was performed to compare the computationally predicted $\mathrm{C} 2-\mathrm{C} 8 / \mathrm{C} 3-\mathrm{C} 16$ globular structure to the synthesized $\mathrm{C} 2-\mathrm{C} 16 / \mathrm{C} 3-\mathrm{C} 8$ ribbon structure. Assignment of ${ }^{1} \mathrm{H}$ resonances for KTM was achieved using standard methods [40]. A combination of COSY, TOCSY, and NOESY spectra in both $30 \% \mathrm{ACN} / 70 \%$ water and $30 \% \mathrm{ACN} / 70 \% \mathrm{D}_{2} \mathrm{O}$ were used to reduce ambiguities in assignment. Fifteen amino acid spin systems were assigned in the fingerprint region (7.6-8.8 ppm), and the final amino acid, P6, was identified in the $\alpha$-proton region (5.2-3.8 ppm). Table 1 shows the chemical shift assignments for each of the sixteen amino acids in KTM, and Figure 5 shows the calculated random coil chemical shift difference. Table 2 shows the 32 nuclear Overhauser effect (NOE) distance restraints, four dihedral angles, and two disulfide bond constraints that were input into CYANA for structure calculation. NMR structure determination using CYANA [41] confirms the peptide backbone exists as a ribbon, lacking a defined $\alpha$-helix. Despite a reasonably rigid scaffold constrained by two disulfide bonds, the backbone structure of KTM reflects the influence of side chain mobility particularly evident for the aromatic Tyr and Trp residues. Figure 6 A-B shows a comparison 
of the NMR-derived structures (A), and an overlay of the median NMR-derived structure (cyan) to the computationally predicted structure (magenta) for KTM (B). The root-mean-squared deviation (RMSD) for backbone atoms to a mean structure was calculated to be $1.7 \pm 0.4 \AA$ (Figure 6A). The RMSD between the NMR solution structure of KTM and the computationally predicted KTM structure was $3.5 \AA$, which is expected considering the computationally predicted structure maintained the globular disulfide connectivity consistent with $\alpha$-CTx MII (Figure 6B).

Table 1. Proton chemical shift assignments for amino acids in KTM.

\begin{tabular}{ccccc}
\hline Residue & NH & $\alpha \mathbf{H}$ & $\beta \mathbf{H}$ & Other \\
\hline W1 & 8.31 & 4.62 & $3.61,3.44$ & $2 \mathrm{H} \mathrm{7.37,} \mathrm{N1H} \mathrm{10.23}$ \\
\hline C2 & 8.57 & 5.33 & $3.71,2.92$ & \\
\hline C3 & 8.63 & 5.14 & $2.96,3.67$ & \\
\hline S4 & 8.53 & 4.23 & 3.97 & $\delta \mathrm{H} \mathrm{3.70,3.58}$ \\
\hline Y5 & 7.91 & 4.84 & $3.39,3.23$ & \\
\hline P6 & & 4.07 & $1.99,2.20$ & \\
\hline G7 & 7.96 & 4.08 & & $2 \mathrm{H} \mathrm{7.74,} \mathrm{N1H} \mathrm{10.52,} \mathrm{7H} \mathrm{7.88}$ \\
\hline C8 & 8.40 & 4.53 & $3.62,3.11$ & \\
\hline Y9 & 7.78 & 4.57 & $3.32,3.60$ & \\
\hline W10 & 8.09 & 4.84 & 3.21 & \\
\hline S11 & 8.62 & 4.33 & 3.83 & \\
\hline S12 & 8.38 & 4.25 & 3.88 & \\
\hline S13 & 8.74 & 4.40 & 4.01 & \\
\hline K14 & 8.19 & 4.66 & $1.72,1.56$ & \\
\hline W15 & 7.64 & 5.12 & $3.13,3.31$ & \\
\hline C16 & 8.47 & 5.08 & $3.57,3.04$ & \\
\hline & & & & \\
\hline
\end{tabular}

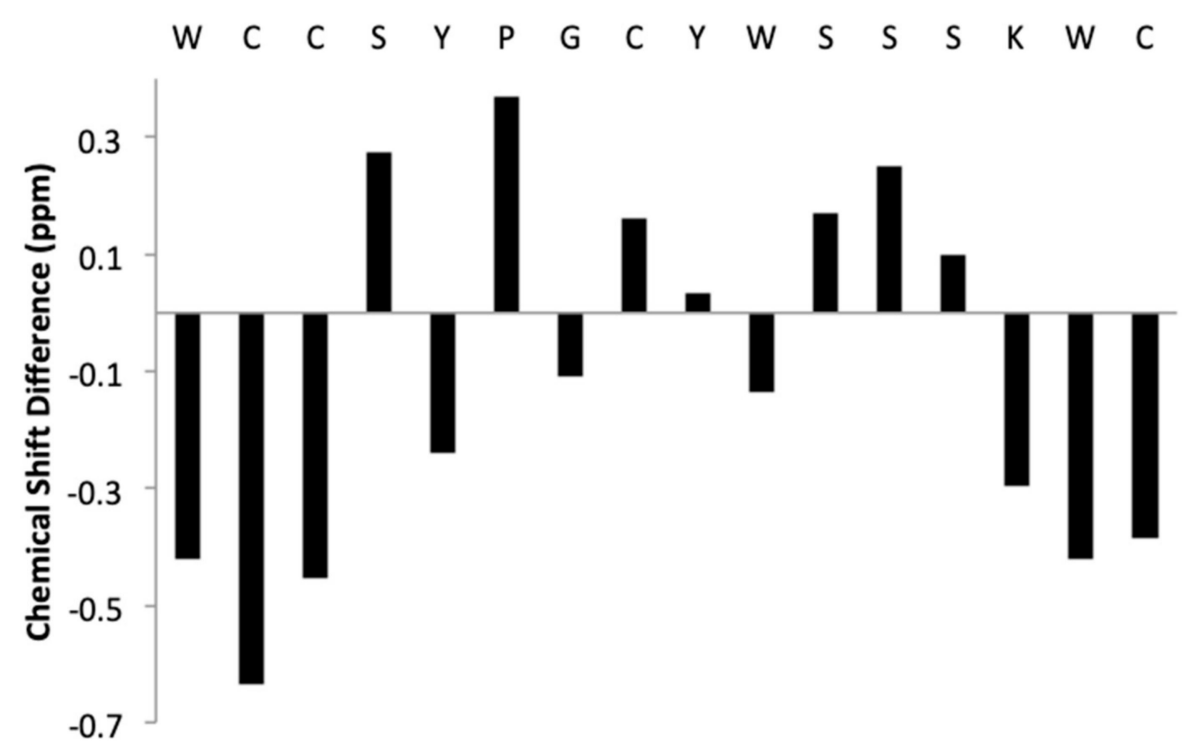

Figure 5. Chemical shift difference between $\alpha$-protons of amino acids in KTM and predicted random coil chemical shifts for the same amino acids. 
Table 2. Nuclear magnetic resonance (NMR) restraints used in CYANA, and the resulting structure statistics for KTM.

\begin{tabular}{|c|c|}
\hline \multicolumn{2}{|l|}{ Experimental Data } \\
\hline Distance Restraints & \\
\hline Total NOE & 32 \\
\hline Intra-residue & 12 \\
\hline Inter-residue & 20 \\
\hline Sequential & 18 \\
\hline Short range & 30 \\
\hline Medium range & 2 \\
\hline Long range & 0 \\
\hline$\phi$ Dihedral angle restraints & 4 \\
\hline Disulfide restraints & 2 \\
\hline Total NOE violations exceeding $0.3 \AA$ & 0 \\
\hline Total NOE violations exceeding $0.3 \AA$ & 0 \\
\hline \multicolumn{2}{|l|}{ Structure Statistics } \\
\hline \multicolumn{2}{|l|}{ Average pairwise RMSD $(\AA)$} \\
\hline Backbone atoms (residues 1-16) & $1.7 \pm 0.5$ \\
\hline Heavy atoms (residues 1-16) & $3.0 \pm 0.7$ \\
\hline \multicolumn{2}{|l|}{ Ramachandran statistics } \\
\hline \%Favored and allowed regions & 100 \\
\hline$\%$ Disallowed regions & 0 \\
\hline
\end{tabular}
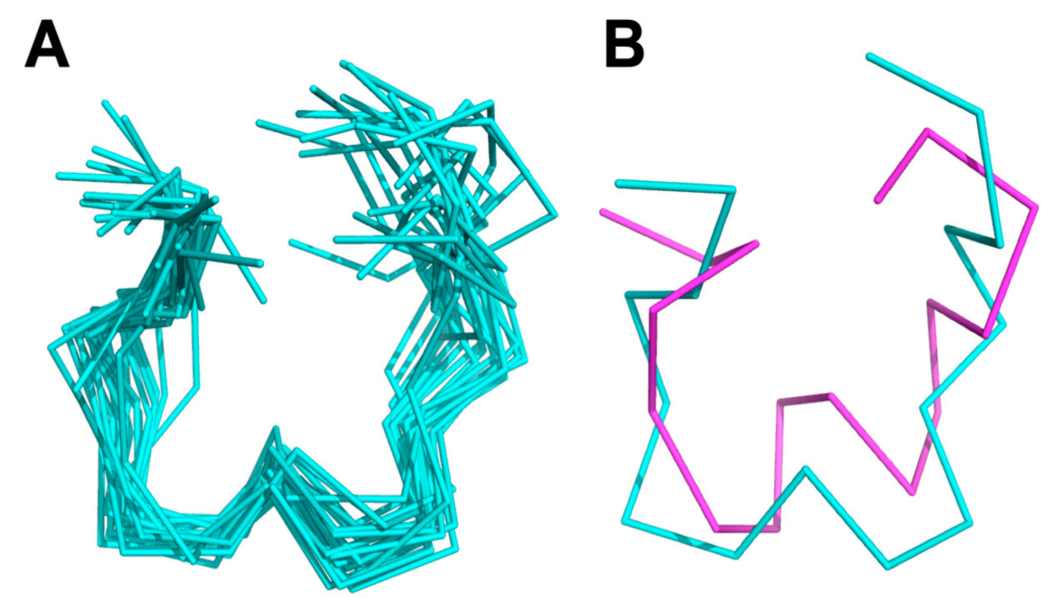

Figure 6. NMR solution structure of KTM, where (A) is a ribbon representation of an ensemble of the 20 lowest energy structures, with an average RMSD to the mean structure of $1.7 \pm 0.4 \AA$, and (B) represents an overlay of the mean calculated structure from NMR (cyan) and the computationally predicted structure (magenta) that have an average RMSD of $3.5 \AA$.

\subsection{Molecular Dynamics Simulations}

Figure 7 shows the root-mean-square fluctuations (RMSFs) for each residue after a 50 ns molecular dynamics simulation in Gromacs. According to these results, the side chains of KTM are expected to have a high degree of fluctuation. Residues W1, S4-G7, and K14, particularly, show the highest degrees of fluctuation. 


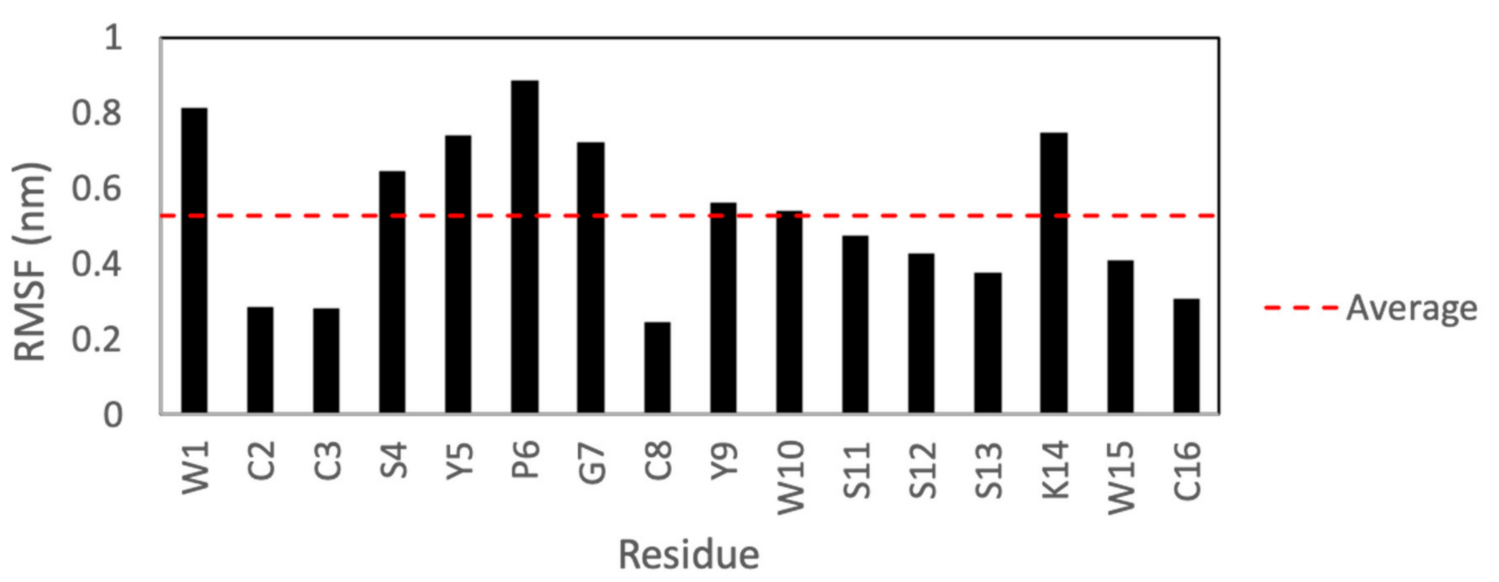

Figure 7. Root mean square fluctuations for each of the 16 residues of KTM over a 50 ns MD simulation. Residues W1, S4-G7, and K14 were observed to exhibit the greatest root-mean-square fluctuations (RMSFs).

\section{Discussion}

Qualitative evaluation of KTM bioactivity with the PC12 assay confirmed that KTM reduced the amount of dopamine released from the cells, presumably by blocking nAChRs (Figure 2) [11]. To assess whether KTM acted on $\mathrm{r} \alpha 3 \beta 2-\mathrm{nAChRs}$, as it was designed to do, quantitative evaluation of its bioactivity was performed by two-electrode voltage clamp electrophysiology using Xenopus oocytes expressing r $\alpha 3 \beta 2$-nAChRs. KTM caused blockage of r $\alpha 3 \beta 2$-nAChRs with an $\mathrm{IC}_{50}$ of $0.19 \pm 0.02 \mathrm{nM}$ as compared to $0.35 \pm 0.08 \mathrm{nM}$ for $\alpha$-CTx MII (Figure 3). The similar efficacy of KTM compared to that of $\alpha$-CTx MII supports the premise that the synthetic peptide is an effective antagonist of $r \alpha 3 \beta 2-n A C h R$.

KTM exhibited potent inhibition of $\mathrm{r} \alpha 3 \beta 2$-nAChRs commensurate with $\alpha-\mathrm{CTx}$ MII, necessitating validation of synthetic peptide structure for comparison to the computationally predicted structure. The primary sequence of KTM differs from $\alpha$-CTx MII with regard to nine of the sixteen amino acids. First, the NMR structure of KTM was determined using the method established by Wüthrich [40]. Sequence, distance, dihedral angle, and disulfide bond restraints were entered into CYANA for structure calculation. It was anticipated that the disulfide bonds in synthesized KTM, that were formed by undirected folding, and those of native $\alpha$-CTx MII, would be consistent. Despite extensive analysis of NMR data and restraint assignment, CYANA failed to provide an ensemble of KTM backbone structures that converged better than a RMSD of $2.5 \AA$. An evaluation of the CD spectrum and partial reduction mass spectrometry data provided definitive evidence that the disulfide pattern for KTM synthesized by undirected folding was not the same as the globular fold of $\alpha$-CTx MII (C1-C3, $\mathrm{C} 2-\mathrm{C} 4)$, but rather was consistent with the ribbon fold observed for an isomer of $\alpha$-CTx AuIB (C1-C4, C2-C3) (see Figure S1). An ordered secondary structure commensurate with the common $\alpha$-CTx 4/7 loop peptide $\alpha$-helix of MII was not expected due to the $\alpha$-helical content for KTM interpreted as $12.5 \%$ based on CD spectrum, which is much lower than the $\alpha$-helical content for $\alpha$-CTx MII of $38.1 \%$ (Figure 4). Upon changing the disulfide bond connectivity restraints in CYANA, a final set of 20 KTM structures with an RMSD among backbone atoms of $1.7 \pm 0.5 \AA$ was obtained with no distance restraint or conformation violations detected (Figure 6). The RMSD between the NMR solution structure of KTM and the computationally predicted structure of KTM was $3.5 \AA$. The rough similarity in backbone shape between the computationally predicted and NMR solution structure generated for KTM, despite differing disulfide linkages, is suspected to be the reason for the observed nAChR bioactivity. Preliminary analysis of NMR data for chemical shift deviation from random coil was used as an indication of expected KTM peptide rigidity (Figure 5). Random coil peptides generally show amide proton chemical shifts between 8.09 and 8.45 ppm [42], while those in KTM were between 7.64 and 8.74, indicating regions of structure rigidity. Similarly, random coil peptides generally show $\alpha$-proton chemical shifts between 4.4 and 4.8 ppm, while those in KTM were between 4.07 and 5.33 ppm. 
Thus, the chemical shift variation observed for amide and $\alpha$-protons in KTM (Figure 5) were consistent with data expected for a peptide of reasonably rigid scaffold.

The relatively low number of distance and angle constraints for KTM was due to challenges associated with a 1942 Da peptide and the high redundancy of amino acids (4C, 4S, 3W, 2Y), resulting in many proton chemical shifts in similar or identical electronic environments. The interpretation of NMR spectra for KTM was severely complicated due to peak overlap, ring-flipping of aromatic side chains, and spectral shift between $\mathrm{H}_{2} \mathrm{O}$ and $\mathrm{D}_{2} \mathrm{O}$ spectra. Figure 8 shows an overlay of the fingerprint region for COSY and TOCSY spectra used to assign the spin systems in KTM from which the chemical shift assignments as summarized in Table 1 were generated. The proton chemical shifts for aromatic amino acids are largely missing from Table 1 due to assignment ambiguity originating from the three tryptophan and two tyrosine residues with overlapping chemical shifts further exacerbated by ring flipping. Additional structure challenges arose from the molecular weight of KTM correlating to the NOE detection minimum, limiting the number of medium- and long-range NOEs that could be assigned as restraints. Conotoxin structure determination by NMR is inherently difficult due to weak NOE signals, limited distance for protons to provide an assignable NOE, and side chain mobility that provides conformations where protons enter in and out of detectable proximity to one another [43]. Additionally, the high number of heavy aromatic side chains in KTM is suspected to contribute to inherent flexibility.

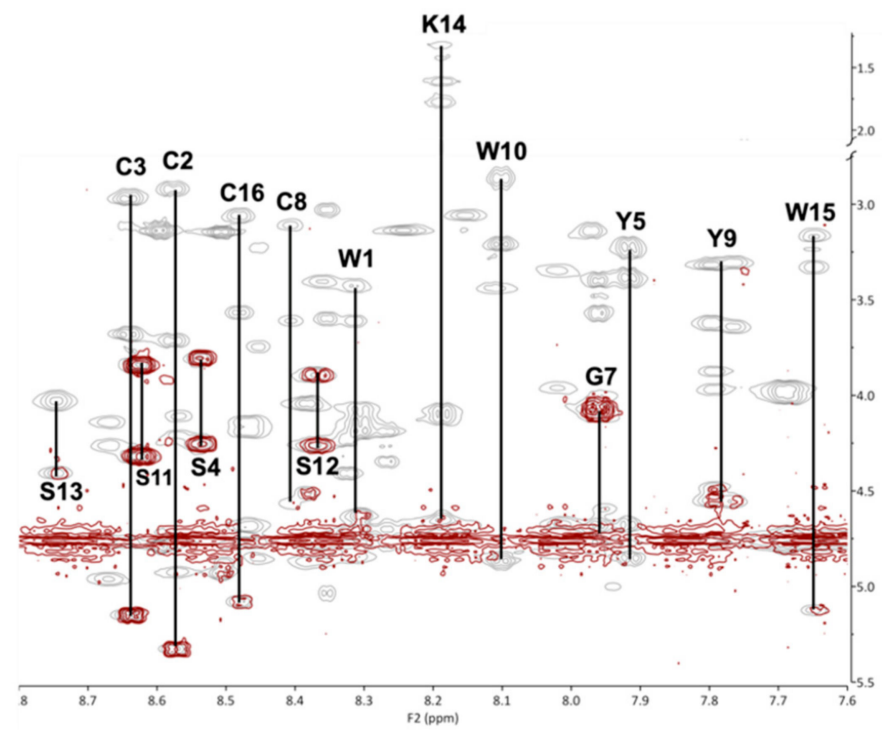

Figure 8. Fingerprint region of COSY (red) and TOCSY (grey) spectra overlaid for residues $1-5$ and 7-16, acquired at $600 \mathrm{MHz}$ for KTM at $298 \mathrm{~K}$ in 30\% ACN/70\% $\mathrm{H}_{2} \mathrm{O}$. Residue assignments are indicated by their one-letter amino acid code.

Perhaps the most striking finding of this study was that KTM, which was predicted to act on r $\alpha 3 \beta 2$-nAChRs, did indeed do so, and with very high potency, despite having a ribbon-type $\alpha$-CTx disulfide connectivity. There is precedent for ribbon isomers of Framework I $\alpha$-CTxs with binding affinity for r $\alpha 3 \beta 2$-nAChRs. Dutton, et al. (2002) characterized a non-native ribbon disulfide bond isomer of recombinant $\alpha$-CTx AuIB that, while more flexible than the native globular isomer, exhibited 10 times more potent activity with nAChRs in rat parasympathetic neurons than the native globular isomer $[36,37]$. They presumed that the flexibility of the ribbon isomer allowed the peptide to adopt a complementary conformation with the receptor binding site. KTM is the first example of a Framework I $\alpha$-CTx with ribbon fold to demonstrate sub-nanomolar inhibition of $\mathrm{r} \alpha 3 \beta 2$-nAChRs. To briefly explore why KTM exhibits functionality consistent with $\alpha$-CTx MII, a comparison of the electrostatic maps of $\alpha$-CTx MII and KTM was performed using the ABPS Electrostatics plugin in PyMOL [44] after performing a $50 \mathrm{~ns}$ molecular dynamics simulation in Gromacs. The simulation shows that the side 
chains for W1, S4-G7, and K14 have a high degree of fluctuation (Figure 7), and that loop 2 is especially dynamic (Figure 9), indicating that a single model may not well represent the peptide.
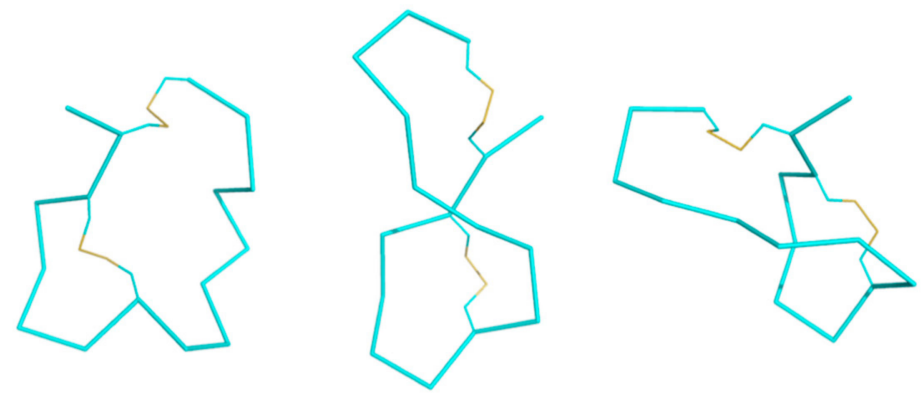

Figure 9. Ribbon structures of KTM at 0 ns (left), $25 \mathrm{~ns}$ (middle), and $50 \mathrm{~ns}$ (right) in the molecular dynamics simulation. Loop 2 appears to swing across the peptide over the course of the simulation.

Figure 9 shows the progression from left to right of representative structures through the course of a molecular dynamics simulation with snapshots taken at 0,25 , and $50 \mathrm{~ns}$ run time. The dynamic movement of the second loop is exemplified throughout the course of the MD trial. To illustrate the dynamic flexibility of KTM and its potential for induced fit into the binding site of $\mathrm{r} \alpha 3 \beta 2 \mathrm{nAChR}$, the electrostatic surfaces of KTM at $0 \mathrm{~ns}$ (Figure 10A) and at $50 \mathrm{~ns}$ (Figure 10C) are shown in comparison to $\alpha$-CTx MII (Figure 10B). KTM can adopt both a structure with a surface volume much larger than $\alpha$-CTx MII with multiple points of protrusion from aromatic side chains and a hollow core (Figure 10A), as well as a more compact structure that more closely resembles that of $\alpha$-CTx MII as loop 2 appears to flex inward (Figure 10C).

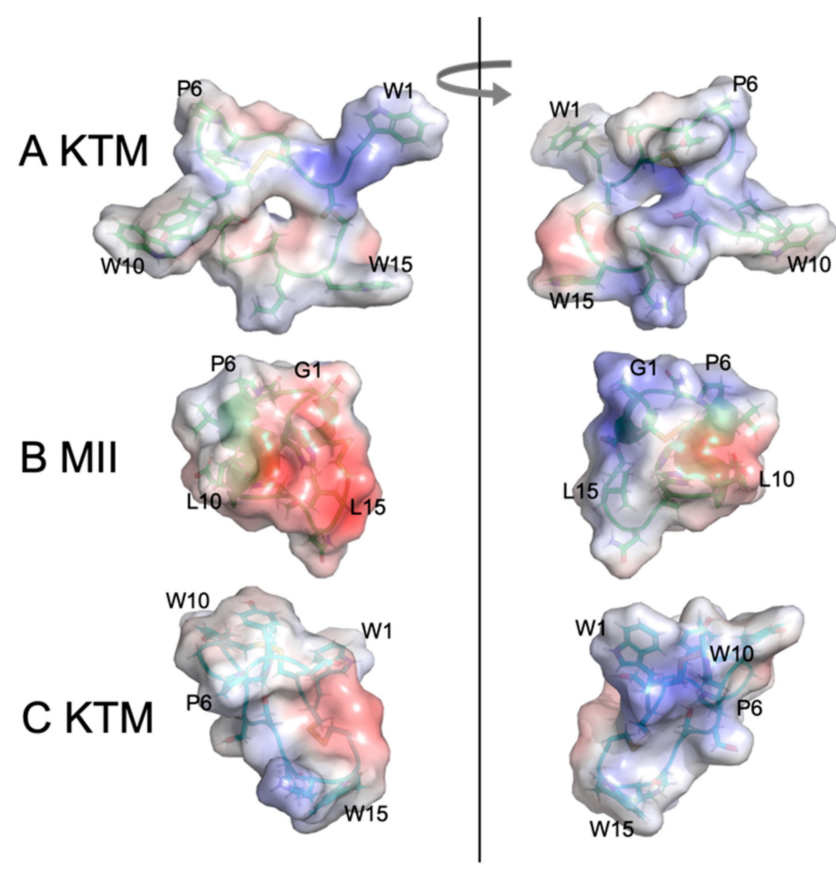

Figure 10. Electrostatic maps of KTM at 0 ns of the molecular dynamics simulation (A), $\alpha$-CTx MII (B), and KTM at $50 \mathrm{~ns}$ of the molecular dynamics simulation (C). Images on the left and right are rotated by 180 degrees.

Figure 10 shows the convergence from NMR-derived structure ( $0 \mathrm{~ns} \mathrm{MD}, \mathrm{A})$ to computationally refined KTM conformation upon 50 ns simulation (C), compared to the structure of $\alpha$-CTx MII (B). The MD simulation provides correlation between KTM and MII that reflects common surface 
electrostatics and structure topography attributes that may be used to explain the observed potent activity of KTM on nAChRs (Figure 3).

\section{Materials and Methods}

\subsection{Synthesis}

KTM was synthesized by and purchased from CS Bio (Menlo Park, CA) in folded form as a white powder. Following solid phase peptide synthesis, disulfide linkages were allowed to form into the most thermodynamically stable conformation under reducing conditions. The major isomer was collected by HPLC at ca. $98.36 \%$ purity. The peptide was collected at $10.71 \mathrm{~min}$ using a $20 \%-50 \%$ gradient of Buffer B $\left(0.1 \%\right.$ TFA in ACN) over a 20 min run time, where Buffer A was $0.1 \%$ TFA in $\mathrm{H}_{2} \mathrm{O}$. The column was a Phenomenex Luna $C_{18}$ with specifications of $5 \mu \mathrm{M}, 100 \AA, 4.6 \times 250 \mathrm{~mm}$. The flow rate was $1 \mathrm{~mL} / \mathrm{min}$ and the injection volume was $20 \mu \mathrm{L}$. Peptide identity was confirmed by mass spectrometry where the expected molecular weight was 1942.21 Da and the found molecular weight was 1941.52 Da.

\subsection{Disulfide Bond Analysis}

Analysis was performed using an UltiMate 3000 HPLC (Thermo Scientific, Waltham, MA, USA) equipped with a Corona Veo RS charged aerosol detector (CAD), an UltiMate 3000 Diode Array Detector (DAD), and MSQ Plus mass spectrometer (MS). HPLC separation of peptide species was achieved using an Acclaim $120 \mathrm{C}_{18}$ column $(2.1 \times 150 \mathrm{~mm}, 3 \mu \mathrm{m})$ (Thermo Fisher), and mobile phases consisting of $0.1 \%$ formic acid (v/v) in water (Buffer A) and $0.1 \%$ formic acid (v/v) in acetonitrile (Buffer B) with a flow rate of $0.3 \mathrm{~mL} / \mathrm{min}$. A linear gradient method beginning at $85 \%$ Buffer $\mathrm{A}$ and $15 \%$ Buffer B, up to $60 \%$ Buffer B over a 25 min run time achieved desired separation from a $10 \mu \mathrm{L}$ sample injection volume. Data were analyzed with the Chromeleon 7.2 Chromatography Data System (Thermo Fisher). The partial reduction strategy of Gray [45] was used to sequentially reduce and alkylate disulfide bonds. Synthetic KTM peptide $(0.1 \mathrm{nmol})$ from CS Bio was dissolved in $1 \mathrm{M}$ equivalent of tris 2-carboxyethyl phosphine (TCEP) in $25 \mathrm{mM}$ ammonium formate, at $\mathrm{pH} 4.5$, and incubated at $37^{\circ} \mathrm{C}$ for $10 \mathrm{~min}$. Following incubation, the reaction mixture was separated by HPLC, and the peptide reduction was monitored by mass spectrometry through observation of a mass increase of $+2 \mathrm{~m} / \mathrm{z}$, corresponding to the peptide with one disulfide bond reduced. Two molar equivalents of $\mathrm{N}$-ethylmaleimide (NEM) were added and the reaction mixture and alkylation was monitored by LC-MS for observation of a mass increase of $+125 \mathrm{~m} / \mathrm{z}$. The increase in $\mathrm{m} / \mathrm{z}$ of +125 in the doubly charged ion equates to a mass shift of $+250 \mathrm{Da}$ in KTM corresponding to the coupling of one thiol to NEM. Peptide fractions, as identified by UV absorbance at $280 \mathrm{~nm}$, were collected manually into $1.5 \mathrm{~mL}$ polypropylene centrifuge tubes and lyophilized to dryness. The resultant di- and tetra-alkylated peptides appeared as dull white powders. Monocyclic intermediates were reconstituted in 1:1 (v/v) acetonitrile/25 mM ammonium formate, reduced with dithiothreitol (DTT) at a final concentration of $10 \mathrm{mM}$ for $1 \mathrm{hr}$ at $37^{\circ} \mathrm{C}$, and alkylated with iodoacetamide (IAA) at a final concentration of $55 \mathrm{mM}$ for $1 \mathrm{hr}$ in the dark at room temperature. The reaction mixture was injected onto the LC-MS to monitor reduction and alkylation by observation of a mass increase of $+59 \mathrm{~m} / \mathrm{z}$, corresponding to the addition of acetamide. Doubly alkylated peptides were submitted for sequence analysis to determine the locations of S-carboxamidomethyl-L-cysteine residues, and confirm the disulfide connectivity (see Figure S1). MS/MS fragmentation for sequence analysis was achieved using a Velos Pro Dual-Pressure Linear Ion Trap mass spectrometer (Thermo Scientific) coupled to a Nanoscale LC system at a flow rate of $300 \mathrm{~nL} / \mathrm{min}$. A fused silica emitter directly attached to the analytical column through a zero dead volume union was used to spray peptides at a voltage of $2.2 \mathrm{kV}$. MS/MS data was collected in data-dependent acquisition mode, using collision-induced dissociation (CID) with a normalized collision energy of $35 \%$ to fragment the precursor ions. MS/MS data for the 10 most abundant precursor ions was selected from the proceeding full MS scan over the m/z range of 300-2000. Proteome Discoverer 2.2 (Thermo Scientific) was used to analyze the data. 


\subsection{Circular Dichroism Spectropolarimetry}

Circular dichroism (CD) spectra were recorded on a Jasco J-810 spectropolarimeter (Jasco, Inc., Easton, MD, USA) with a cell path length of $0.1 \mathrm{~cm}$ at room temperature in a nitrogen atmosphere in water. Scans were acquired from 190 to $250 \mathrm{~nm}$. The bandwidth of $1 \mathrm{~nm}$, a speed of $50 \mathrm{~nm} / \mathrm{min}$, and a resolution of $0.5 \mathrm{~nm}$ were used. A total of 5 scans per sample were averaged, baselines were subtracted, and the sample was run in triplicate. A final concentration of $50 \mu \mathrm{M}$ of each sample was used. Analysis and data processing were carried out with the Jasco system software and Microsoft Excel. Mean residue ellipticity $\left(\theta \mathrm{MRE}\right.$, in $\left.\operatorname{deg} \times \mathrm{cm}^{2} \times \mathrm{dmol}^{-1}\right)$ for each spectrum was calculated from the formula $\theta \mathrm{MRE}=\theta /\left(10 \mathrm{C}_{\mathrm{r}} \times l\right)$, where $\theta$ is the measured ellipticity in millidegrees, $\mathrm{C}_{\mathrm{r}}$ is the molar concentration, and $l$ is the path length in centimeters. The $\alpha$-helical content was estimated from the formula $\theta \mathrm{MRE}=30300 \mathrm{fH}-2340$, where $\mathrm{fH}$ is the fraction of $\alpha$-helical content $(\mathrm{fH} \times 100$, expressed as a percentage) calculated from the $\theta \mathrm{MRE}$ at $222 \mathrm{~nm}$, which is a widely used proxy for helical secondary structure that is useful to assess disruption of the secondary structure, as was performed here [46-48].

\subsection{Nuclear Magnetic Resonance Spectroscopy}

NMR samples were prepared at a concentration of approximately $3 \mathrm{mM}$ in either $30 \%$ deuterated acetonitrile $(\mathrm{d}-\mathrm{ACN}) / 70 \%$ water or $30 \% \mathrm{~d}-\mathrm{ACN} / 70 \%$ deuterium oxide $\left(\mathrm{D}_{2} \mathrm{O}\right)$. $\mathrm{d}-\mathrm{ACN}$ was used due to the limited solubility of KTM in water. $\mathrm{D}_{2} \mathrm{O}$ samples were prepared by dissolving lyophilized sample in $30 \% \mathrm{~d}-\mathrm{ACN} / 70 \% \mathrm{D}_{2} \mathrm{O}$ solvent and immediately acquiring spectra. Two-dimensional ${ }^{1} \mathrm{H}$ NMR experiments and spectral interpretation were performed by established methods [40-42,49-54].

All NMR data were acquired on a $600 \mathrm{MHz}$ Bruker Avance III NMR spectrometer at $298 \mathrm{~K}$. COSY, TOCSY, and NOESY spectra were acquired using water suppression for aqueous samples. A series of NOESY spectra were acquired with mixing times of 150, 200, 250, 300, and $350 \mathrm{~ms}$. TOCSY spectra were acquired with an 80 ms mixing time $\left(30 \% \mathrm{ACN} / 60 \% \mathrm{H}_{2} \mathrm{O} / 10 \% \mathrm{D}_{2} \mathrm{O}\right)$. Parameter set details are provided in Table S1. Spectra were processed in Topspin and analyzed in CCPNMR v2 and v3 [55] to correct resonance shifts, manually pick peaks, and identify spin systems.

\subsubsection{Restraint Set Generation}

Three-bond ${ }^{1} \mathrm{H}^{\mathrm{N}}{ }^{1} \mathrm{H}^{\alpha}$ coupling constant values were determined by visual inspection of a high-resolution 1D ${ }^{1} \mathrm{H}$ spectrum in Topspin. Backbone dihedral phi angle restraints were set to $-120 \pm 40$ for ${ }^{3} J_{\mathrm{HH}}{ }^{1} \mathrm{H}^{\mathrm{N}}-1 \mathrm{H}^{\alpha}$ coupling constant values greater than $7.5 \mathrm{~Hz}$ and to $-65 \pm 25$ for ${ }^{3} J_{\mathrm{HH}}$ ${ }^{1} \mathrm{H}^{\mathrm{N}}{ }_{1} \mathrm{H}^{\alpha}$ coupling constant values less than $5 \mathrm{~Hz}$ [54]. Inter- and intraproton distance ranges were calibrated within CYANA. Distance restraints were derived from NOESY spectra recorded at $298 \mathrm{~K}$ and mixing time of $350 \mathrm{~ms}$.

\subsubsection{Structure Calculation}

Input files were formatted for the CYANA program (v 2.1). The autoassign script in CYANA was used for assignment of 69 hydrogen atom chemical shift values. A chemical shift tolerance of 0.075 was used for both axes. Disulfide bonds were used as distance restraints. CYANA produced an ensemble of 20 top structures based on 32 restraints. The final set of 20 structures gave a root-mean-square deviation among backbone atoms of $1.7 \pm 0.4 \AA$. The structure most representative of the mean structure was determined with WHATIF [56]. Procheck [57] and Verify3D [58] online servers were used to assess structure quality. Molprobity scores are reported in Table S2 [59].

\subsection{PC12 Assay}

Cell culture and bioactivity assessment were performed according to Marquart, et al. [11]. The PC12 assay was performed using a Biotek Synergy H1 microplate reader (Winooski, VT). All chemicals were purchased at the highest purity available $(>95 \%)$ from Fisher Scientific. ATCC ${ }^{\circledR}$ CRL1721 ${ }^{\mathrm{TM}}$ PC12 cells were provided by the Biomolecular Research Center at Boise State University. 


\subsubsection{Cell Culture}

PC12 cells were cultured into laminin-coated flasks and triturated to detach. Cells were grown in a T-75 flask until dense enough to plate onto a laminin-coated flat-bottom well plate and treated with starvation media ( $30 \mathrm{ng} / \mathrm{mL}$ NGF $2.5 \mathrm{~S}, 1 \mu \mathrm{M}$ nicotine) for 3-4 days before performing the assay.

\subsubsection{Assay}

Cells were washed with Locke's solution before introducing the assay solution, which included $10 \mu \mathrm{M}$ toxin, $0.8 \mathrm{ng} / \mathrm{mL}$ POD, $25 \mathrm{ng} / \mathrm{mL} \mathrm{MAO}$, and $50 \mu \mathrm{M}$ luminol. The luminol was added to quench any dissolved oxygen in the cell environment and the assay solution. Cells were allowed to equilibrate for 5-10 min before the addition of $2 \mathrm{mM}$ luminol and $50 \mu \mathrm{M} \mathrm{ACh}$, for a total well volume of $100 \mu \mathrm{L}$. Upon equilibration, the luminescence signal was detected. (-)MAO and (-)cells were used as negative controls. Assays were performed at $37^{\circ} \mathrm{C}$, detecting luminescence for $1-2 \mathrm{~min}$ per well. Luminescence response curves were then integrated as a measure of dopamine secretion inhibition resultant from peptide treatment for analysis.

\subsection{Electrophysiology}

\subsection{1. $\mathrm{r} \alpha 3 \beta 2-\mathrm{nAChR}$ expression in Xenopus laevis oocytes}

cDNA preparation, oocyte harvest, expression of nAChR subunits, and culture were performed as described previously [60]. The rat isoforms of neuronal nAChR subunits $\alpha 3$ and $\beta 2$ in vectors pSP64 and pSP65, respectively, were generously provided by Dr. Steven Heinemann (Salk Institute, San Diego, CA). All salts and antibiotics were obtained from Sigma or Fisher Scientific. Oocytes were extracted from adult Xenopus according to protocols approved by the Institutional Animal Use and Care Committee at ISU and according to AAALAC guidelines. Oocytes were isolated with $2 \mathrm{mg} / \mathrm{L}$ collagenase and cultured at $17.5^{\circ} \mathrm{C}$ in sterile ND-96 saline containing $96 \mathrm{mM} \mathrm{NaCl}, 2 \mathrm{mM}$ $\mathrm{KCl}, 1.8 \mathrm{mM} \mathrm{CaCl}_{2} 1 \mathrm{mM} \mathrm{MgCl}_{2}$, and $5 \mathrm{mM}$ 4-(2-hydroxyethyl)-1-piperazineethanesulfonic acid (HEPES), with $5 \mathrm{mM}$ Na pyruvate, $2 \%$ horse serum, $100 \mathrm{mg} / \mathrm{L}$ gentamicin, $100 \mathrm{mg} / \mathrm{L}$ amikacin, $50 \mathrm{mg} / \mathrm{L}$ ciprofloxacin, $20 \mathrm{mg} / \mathrm{L}$ tetracycline, and $100 \mathrm{U} / \mathrm{L}$ streptomycin/penicillin, at $\mathrm{pH}$ 7.4. Messenger RNA was transcribed as detailed previously; $\alpha 3$ and $\beta 2$ mRNA was coinjected at $41 \mathrm{~nL}$ into oocytes 3 to 5 days prior to recordings.

\subsubsection{Two-Electrode Voltage Clamp}

To record the response to ACh, oocytes were impaled with glass electrodes containing $3 \mathrm{M}$ $\mathrm{KCl}$ for two-electrode voltage clamp electrophysiology. Oocytes were placed in a $300 \mu \mathrm{L}$ recording chamber and perfused at $1.0 \mathrm{~mL} / \mathrm{min}$ with ND-96 saline containing atropine sulfate $(1 \mathrm{mM})$, at room temperature. Voltage clamp was performed with an OC-725C amplifier (Warner Instruments, Hamden, CT) with data acquisition achieved through an ITC-18 interface and PatchMaster 2.35 software (HEKA Instruments, Bellmore, NY). Oocytes were held at $-70 \mathrm{mV}$ between trials, and at $-80 \mathrm{mV}$ during trials of ACh application. During perfusion, a 20 to $50 \mathrm{~ms}$ pulse of ACh chloride (0.01 M, Sigma, St. Louis, $\mathrm{MO}$ ) in the bath solution was locally applied from a glass capillary tube positioned above the oocyte, with pressure ejection using a PicoSpritzer II valve controller (General Valve Corporation, Fairfield, $\mathrm{NJ}$ ). Once a reliable response was obtained, the chamber was perfused with $\alpha$-CTx MII or KTM for $15 \mathrm{~min}$, and the ACh pulse was applied. Inward sodium current amplitudes for each toxin trial were normalized against the control response to $\mathrm{ACh}$ as percent response. Each data point of the dose response curve represents the average value of 8 to 12 measurements. Dose-dependent response curves were fit to Equation (1):

$$
\% \text { response }=100 /\left[1+\left([\text { toxin }] / \mathrm{IC}_{50}\right)^{n}\right],
$$

where $n$ is the Hill coefficient and $\mathrm{IC}_{50}$ is the inhibitory concentration at half-maximal block, by non-linear regression analysis using Igor Pro 6.37 (Wavemetrics, Lake Oswego, OR, USA). 


\subsection{Molecular Dynamics Simulations}

Molecular dynamics simulations were performed with the AMBER03 force-field parameter set [61] using the Gromacs 2019 software package [62]. The median conformation for KTM from the top 20 NMR solution structures was selected as the input structure for MD simulation in Gromacs. Since the NMR spectra were acquired for a sample in 30\% acetonitrile/70\% water, the solvated box was obtained by filling a dodecahedral box with the appropriate number of acetonitrile molecules to achieve the desired mixed solvent proportions. A topology for acetonitrile was created for this purpose. The shortest distance of peptide atoms from the box boundary was $1.2 \AA$. Simulations were carried out at $300 \mathrm{~K}$ in a periodic box with a minimum-image convention. The integration step was $1 \mathrm{fs}$, and total duration of each run was $50 \mathrm{~ns}$. Water, acetonitrile, and ions were temperature coupled. Energy minimizations and $\mathrm{N}, \mathrm{V}, \mathrm{T}$ and $\mathrm{N}, \mathrm{P}, \mathrm{T}$ equilibrations were performed before running the simulation. A 500 ps equilibration was conducted under the NVT ensemble using a velocity-rescale thermostat at $300 \mathrm{~K}$ with a coupling time constant of $0.1 \mathrm{ps}$. A subsequent 500 ps NPT equilibration was performed using the isotropic Berendsen barostat with a time constant of $0.1 \mathrm{ps}$. Simulations and models were visualized in PyMOL [44].

\section{Conclusions}

This investigation sought to validate the accuracy and usefulness to rationally design a selective antagonist of a specific nAChR isoform based on the well characterized marine drug $\alpha$-CTx MII. Synthetic KTM peptide was confirmed to be a potent sub-nanomolar inhibitor of $\mathrm{r} \alpha 3 \beta 2 \mathrm{nAChRs}$. It was expected that KTM would fold into the same $\mathrm{C} 1-\mathrm{C} 3$ and $\mathrm{C} 2-\mathrm{C} 4$ disulfide pattern, consistent with $\alpha$-CTx MII. Instead, the folding of KTM resulted in a C1-C4 and C2-C3 ribbon Framework I $\alpha$-CTx, consistent with the recombinant isomer of $\alpha$-CTx AuIB $[36,37]$. It has been stated in the literature that correct folding of synthetic peptides is critical to the maintenance of biological activity, but in the instance of $\mathrm{KTM}$, the globular disulfide pattern is not the same as that found in $\alpha$-CTx MII, but rather resembles the ribbon-connectivity studied for $\alpha$-CTx AuIB [36,37]. KTM is the first example of sub-nanomolar $\mathrm{nAChR}$ antagonism by a Framework I $\alpha$-CTx of ribbon-connectivity. A compelling next step for this work would be the directed folding of KTM to assess whether the potency of the globular-connectivity Framework I peptide may be further enhanced for nAChR inhibition. Validation of computationally predicted peptide binding and biological activity may lead to a better understanding of molecular probes for the treatment of neurological diseases like Parkinson's Disease. Drugs that selectively target human $\alpha 6 \alpha 4 \beta 2 \beta 3 \mathrm{nAChR}$ isoforms could be used as new therapies with fewer side effects than existing treatments. The current study offers a workflow to begin the search for drug therapies inspired by marine natural products.

Supplementary Materials: The following are available online at http:/www.mdpi.com/1660-3397/17/12/669/s1, Table S1: Parameter set details for NMR experiments.; Table S2: Molprobity scores for NMR ensemble; Figure S1: Annotated MS-MS spectrum of relevant distinguishing $B$ and $Y$ fragments.

Author Contributions: This manuscript was made possible by the collaborative effort of a team of researchers that contributed in the following ways, conceptualization, M.D.K., O.M.M. and L.A.M., M.W.T; methodology, L.A.M., M.W.T., J.R.G., L.R.W. and O.M.M.; software, M.D.K., L.R.W. and M.W.T.; validation, L.A.M., M.W.T., L.R.W., J.R.G. and O.M.M.; formal analysis, L.A.M., M.W.T, J.R.G., L.R.W. and O.M.M.; investigation, L.A.M. and M.W.T.; resources, O.M.M. and J.R.G.; data curation, L.A.M., M.W.T., L.R.W., M.D.K, J.R.G. and O.M.M.; writing—original draft preparation, L.A.M.; writing—review and editing, L.A.M., M.W.T, L.R.W., M.D.K., J.R.G. and O.M.M.; visualization, L.A.M., M.D.K., L.R.W. and J.R.G.; supervision, O.M.M., L.R.W. and J.R.G.; project administration, O.M.M.; funding acquisition, O.M.M. and J.R.G.

Funding: We acknowledge financial support for Matthew Turner and Leanna Marquart provided by Institutional Development Awards (IDeA) from the National Institute of General Medical Sciences of the National Institutes of Health under Grants \#P20GM103408 (INBRE) and P20GM109095 (COBRE in Matrix Biology); support for Dr. James Groome was provided by the same INBRE award (ISU sub-award SI3394-SB-825965). We also acknowledge the support from the Biomolecular Research Center at Boise State University with funding from the National Science Foundation, Grants \#0619793 and \#0923535; the MJ Murdock Charitable Trust, Idaho State Board of Education, and Research Corporation. A separate NSF CRIF-MU/RUI Grant No. 0639251 provided funding for 
the NMR spectrometer. Contents are solely the responsibility of the authors and do not necessarily represent the official views of $\mathrm{NIH}$.

Acknowledgments: We wish to thank Tim Andersen for years of collaboration in the development of the DockoMatic software, Thomas Long for his creativity to produce the GAMPMS application that led to the sequence for KTM. The rat isoforms of neuronal nAChR subunits $\alpha 3$ and $\beta 2$ in vectors pSP64 and pSP65, respectively, were generously provided by Steven Heinemann (Salk Institute, San Diego, CA, USA). We wish to acknowledge the Department of Chemistry and Biochemistry, Graduate College, and Research Office at Boise State University for access to graduate student stimulus funds that made this work possible.

Conflicts of Interest: The authors declare no conflict of interest.

\section{References}

1. Kaas, Q.; Yu, R.L.; Jin, A.H.; Dutertre, S.; Craik, D.J. ConoServer: Updated content, knowledge, and discovery tools in the conopeptide database. Nucleic Acids Res. 2012, 40, D325-D330. [CrossRef] [PubMed]

2. Albuquerque, E.X.; Pereira, E.F.R.; Alkondon, M.; Rogers, S.W. Mammalian Nicotinic Acetylcholine Receptors: From Structure to Function. Physiol. Rev. 2009, 89, 73-120. [CrossRef] [PubMed]

3. Quik, M.; Wonnacott, S. alpha 6 beta 2 and alpha 4 beta 2 Nicotinic Acetylcholine Receptors as Drug Targets for Parkinson's Disease. Pharmacol. Rev. 2011, 63, 938-966. [CrossRef] [PubMed]

4. Quik, M.; Bordia, T.; O'Leary, K. Nicotinic receptors as CNS targets for Parkinson's disease. Biochem. Pharmacol. 2007, 74, 1224-1234. [CrossRef] [PubMed]

5. Sharma, G.; Vijayaraghavan, S. Nicotinic receptors: Role in addiction and other disorders of the brain. Subst. Abus. Res. Treat. 2008, 81-95. [CrossRef]

6. Young, J.W.; Geyer, M.A. Evaluating the role of the alpha-7 nicotinic acetylcholine receptor in the pathophysiology and treatment of schizophrenia. Biochem. Pharmacol. 2013, 86, 1122-1132. [CrossRef] [PubMed]

7. Lombardo, S.; Maskos, U. Role of the nicotinic acetylcholine receptor in Alzheimer's disease pathology and treatment. Neuropharmacology 2015, 96, 255-262. [CrossRef]

8. Turner, M.W.; Marquart, L.A.; Phillips, P.D.; McDougal, O.M. Mutagenesis of alpha-Conotoxins for Enhancing Activity and Selectivity for Nicotinic Acetylcholine Receptors. Toxins 2019, 11, 29. [CrossRef]

9. Yu, R.L.; Kompella, S.N.; Adams, D.J.; Craik, D.J.; Kaas, Q. Determination of the alpha-Conotoxin Vc1.1 Binding Site on the alpha 9 alpha 10 Nicotinic Acetylcholine Receptor. J. Med. Chem. 2013, 56, 3557-3567. [CrossRef]

10. Bordia, T.; Grady, S.R.; McIntosh, J.M.; Quik, M. Nigrostriatal damage preferentially decreases a subpopulation of alpha 6 beta 2 nAChRs in mouse, monkey, and Parkinson's disease striatum. Mol. Pharmacol. 2007, 72, 52-61. [CrossRef]

11. Marquart, L.A.; Turner, M.W.; McDougal, O.M. Qualitative assay to detect dopamine release by ligand action on nicotinic acetylcholine receptors. Toxins 2019, 11, 682. [CrossRef]

12. Kuryatov, A.; Lindstrom, J. Expression of Functional Human alpha 6 beta 2 beta 3 Acetylcholine Receptors in Xenopus laevis Oocytes Achieved through Subunit Chimeras and Concatamers. Mol. Pharmacol. 2011, 79, 126-140. [CrossRef] [PubMed]

13. Alkondon, M.; Albuquerque, E.X. Nicotinic receptor subtypes in rat hippocampal slices are differentially sensitive to desensitization and early in vivo functional up-regulation by nicotine and to block by bupropion. J. Pharmacol. Exp. Ther. 2005, 313, 740-750. [CrossRef] [PubMed]

14. Arvin, M.C.; Wokosin, D.L.; Banala, S.; Lavis, L.D.; Drenan, R.M. Probing Nicotinic Acetylcholine Receptor Function in Mouse Brain Slices via Laser Flash Photolysis of Photoactivatable Nicotine. Jove-J. Vis. Exp. 2019, 10. [CrossRef] [PubMed]

15. Engle, S.E.; Broderick, H.J.; Drenan, R.M. Local Application of Drugs to Study Nicotinic Acetylcholine Receptor Function in Mouse Brain Slices. Jove J. Vis. Exp. 2012, 8. [CrossRef]

16. King, M.D.; Long, T.; Pfalmer, D.L.; Andersen, T.L.; McDougal, O.M. SPIDR: Small-molecule peptide-influenced drug repurposing. Bmc Bioinform. 2018, 19, 11. [CrossRef]

17. King, M.D.; Long, T.; Andersen, T.; McDougal, O.M. Genetic Algorithm Managed Peptide Mutant Screening: Optimizing Peptide Ligands for Targeted Receptor Binding. J. Chem. Inf. Modeling 2016, 56, 2378-2387. [CrossRef] 
18. Long, T.; McDougal, O.M.; Andersen, T. GAMPMS: Genetic algorithm managed peptide mutant screening. J. Comput. Chem. 2015, 36, 1304-1310. [CrossRef]

19. Bullock, C.; Cornia, N.; Jacob, R.; Remm, A.; Peavey, T.; Weekes, K.; Mallory, C.; Oxford, J.T.; McDougal, O.M.; Andersen, T.L. DockoMatic 2.0: High Throughput Inverse Virtual Screening and Homology Modeling. J. Chem. Inf. Modeling 2013, 53, 2161-2170. [CrossRef]

20. Jacob, R.B.; Andersen, T.; McDougal, O.M. Accessible High-Throughput Virtual Screening Molecular Docking Software for Students and Educators. PLoS Comput. Biol. 2012, 8, 5. [CrossRef]

21. Jacob, R.B.; Bullock, C.W.; Andersen, T.; McDougal, O.M. DockoMatic: Automated Peptide Analog Creation for High Throughput Virtual Screening. J. Comput. Chem. 2011, 32, 2936-2941. [CrossRef] [PubMed]

22. Leffler, A.E.; Kuryatov, A.; Zebroski, H.A.; Powell, S.R.; Filipenko, P.; Hussein, A.K.; Gorson, J.; Heizmann, A.; Lyskov, S.; Tsien, R.W.; et al. Discovery of peptide ligands through docking and virtual screening at nicotinic acetylcholine receptor homology models. Proc. Natl. Acad. Sci. USA 2017, 114, E8100-E8109. [CrossRef] [PubMed]

23. Kasheverov, I.E.; Chugunov, A.O.; Kudryavtsev, D.S.; Ivanov, I.A.; Zhmak, M.N.; Shelukhina, I.V.; Spirova, E.N.; Tabakmakher, V.M.; Zelepuga, E.A.; Efremov, R.G.; et al. High-Affinity alpha-Conotoxin PnIA Analogs Designed on the Basis of the Protein Surface Topography Method. Sci. Rep. 2016, 6, 11. [CrossRef]

24. Luo, S.L.; Zhangsun, D.T.; Schroeder, C.I.; Zhu, X.P.; Hu, Y.Y.; Wu, Y.; Weltzin, M.M.; Eberhard, S.; Kaas, Q.; Craik, D.J.; et al. A novel alpha 4/7-conotoxin LvIA from Conus lividus that selectively blocks alpha 3 beta 2 vs. alpha 6/alpha 3 beta 2 beta 3 nicotinic acetylcholine receptors. Faseb J. 2014, 28, 1842-1853. [CrossRef] [PubMed]

25. Sali, A.; Blundell, T.L. Comparative Protein Modeling by Satisfaction of Spatial Restraints. J. Mol. Biol. 1993, 234, 779-815. [CrossRef] [PubMed]

26. Friesner, R.A.; Banks, J.L.; Murphy, R.B.; Halgren, T.A.; Klicic, J.J.; Mainz, D.T.; Repasky, M.P.; Knoll, E.H.; Shelley, M.; Perry, J.K.; et al. Glide: A new approach for rapid, accurate docking and scoring. 1. Method and assessment of docking accuracy. J. Med. Chem. 2004, 47, 1739-1749. [CrossRef]

27. Koromyslova, A.D.; Chugunov, A.O.; Efremov, R.G. Deciphering Fine Molecular Details of Proteins' Structure and Function with a Protein Surface Topography (PST) Method. J. Chem. Inf. Modeling 2014, 54, 1189-1199. [CrossRef]

28. Xu, J.; Wang, X.B.; Ensign, B.; Li, M.; Wu, L.; Guia, A.; Xu, J.Q. Ion-channel assay technologies: Quo vadis? Drug Discov. Today 2001, 6, 1278-1287. [CrossRef]

29. Accardi, M.V.; Pugsley, M.K.; Forster, R.; Troncy, E.; Huang, H.; Authier, S. The emerging role of in vitro electrophysiological methods in CNS safety pharmacology. J. Pharmacol. Toxicol. Methods 2016, 81, 47-59. [CrossRef]

30. Armstrong, L.C.; Kirsch, G.E.; Fedorov, N.B.; Wu, C.Y.; Kuryshev, Y.A.; Sewell, A.L.; Liu, Z.Q.; Motter, A.L.; Leggett, C.S.; Orr, M.S. High-Throughput Patch Clamp Screening in Human alpha 6-Containing Nicotinic Acetylcholine Receptors. Slas Discov. 2017, 22, 686-695. [CrossRef]

31. Dunlop, J.; Bowlby, M.; Peri, R.; Vasilyev, D.; Arias, R. High-throughput electrophysiology: An emerging paradigm for ion-channel screening and physiology. Nat. Rev. Drug Discov. 2008, 7, 358-368. [CrossRef] [PubMed]

32. Jacob, R.B.; Bullock, C. Automatic DockOmatic: Ligand and receptor screening made easy. Abstr. Pap. Am. Chem. Soc. 2010, 240, 1.

33. King, M.D.; Phillips, P.; Turner, M.W.; Katz, M.; Lew, S.; Bradburn, S.; Andersen, T.; McDougal, O.M. Computational Exploration of a Protein Receptor Binding Space with Student Proposed Peptide Ligands. Biochem. Mol. Biol. Educ. 2016, 44, 63-67. [CrossRef] [PubMed]

34. Bullock, C.W.; Jacob, R.B.; McDougal, O.M.; Hampikian, G.; Andersen, T. DockoMatic-Automated ligand creation and docking. BMC Res. Notes. 2010, 3, 289-297. [CrossRef] [PubMed]

35. Akondi, K.B.; Muttenthaler, M.; Dutertre, S.; Kaas, Q.; Craik, D.J.; Lewis, R.J.; Alewood, P.F. Discovery, Synthesis, and Structure Activity Relationships of Conotoxins. Chem. Rev. 2014, 114, 5815-5847. [CrossRef] [PubMed]

36. Grishin, A.A.; Wang, C.I.A.; Muttenthaler, M.; Alewood, P.F.; Lewis, R.J.; Adams, D.J. alpha-Conotoxin AuIB Isomers Exhibit Distinct Inhibitory Mechanisms and Differential Sensitivity to Stoichiometry of alpha 3 beta 4 Nicotinic Acetylcholine Receptors. J. Biol. Chem. 2010, 285, 22254-22263. [CrossRef] [PubMed] 
37. Dutton, J.L.; Bansal, P.S.; Hogg, R.C.; Adams, D.J.; Alewood, P.F.; Craik, D.J. A new level of conotoxin diversity, a non-native disulfide bond connectivity in alpha-conotoxin AuIB reduces structural definition but increases biological activity. J. Biol. Chem. 2002, 277, 48849-48857. [CrossRef]

38. Shinohara, H.; Wang, F.F.; Hossain, S.M.Z. A convenient, high-throughput method for enzyme-luminescence detection of dopamine released from PC12 cells. Nat. Protoc. 2008, 3, 1639-1644. [CrossRef]

39. Mir, T.A.; Shinohara, H.; Shimizu, Y. Enzyme-luminescence method: Tool for evaluation of neuronal differentiation based on real-time monitoring of dopamine release response from PC12 cells. Anal. Methods 2011, 3, 837-841. [CrossRef]

40. Wüthrich, K. NMR of Proteins and Nucleic Acids; Wiley: New York, NY, USA, 1986.

41. Güntert, P. Automated NMR Structure Calculation with CYANA. In Protein NMR Techniques; Downing, A.K., Ed.; Humana Press: New York, NY, USA, 2004; Volume 278, pp. 353-378.

42. Wishart, D.S.; Sykes, B.D.; Richards, F.M. The chemical-shift index-A fast and simple method for the assignment of protein secondary structure through nmr-spectroscopy. Biochemistry 1992, 31, 1647-1651. [CrossRef]

43. Robinson, S.D.; Norton, R.S. Conotoxin Gene Superfamilies. Mar. Drugs 2014, 12, 6058-6101. [CrossRef] [PubMed]

44. The PyMOL Molecular Graphics System; 2.1.1; Schrödinger, LLC: New York, NY, USA, 2019.

45. Gray, W.R. Disulfide Structures of Highly Bridged Peptides-A New Strategy for Analysis. Protein Sci. 1993, 2, 1732-1748. [CrossRef] [PubMed]

46. Chen, Y.H.; Yang, J.T. New Approach to Calculation of Secondary Structures of Globular Proteins by Optical Rotatory Dispersion and Circular Dichroism. Biochem. Biophys. Res. Commun. 1971, 44, 1285-1291. [CrossRef]

47. Everhart, D.; Cartier, G.E.; Malhotra, A.; Gomes, A.V.; McIntosh, J.M.; Luetje, C.W. Determinants of potency on alpha-conotoxin MII, a peptide antagonist of neuronal nicotinic receptors. Biochemistry 2004, 43, 2732-2737. [CrossRef] [PubMed]

48. Turner, M.W.; Cort, J.R.; McDougal, O.M. alpha-Conotoxin Decontamination Protocol Evaluation: What Works and What Doesn't. Toxins 2017, 9, 10. [CrossRef]

49. Wishart, D.S.; Bigam, C.G.; Holm, A.; Hodges, R.S.; Sykes, B.D. H-1, C-13 and N-15 Random Coil NMR Chemical-Shifts of the Common Amino-Acids 1. Investigations of Nearest-Neighbor Effects. J. Biomol. Nmr 1995, 5, 332. [CrossRef]

50. Wishart, D.S.; Sykes, B.D.; Richards, F.M. Simple techniques for the quantification of protein secondary structure by H-1-NMR spectroscopy. Febs. Lett. 1991, 293, 72-80. [CrossRef]

51. Bax, A. Two-dimensional NMR and protein structure. Annu. Rev. Biochem. 1989, 58, 223-256. [CrossRef]

52. Jeener, J.; Meier, B.H.; Bachmann, P.; Ernst, R.R. Investigation of exchange processes by 2-dimensional NMR-spectroscopy. J. Chem. Phys. 1979, 71, 4546-4553. [CrossRef]

53. Braunschweiler, L.; Ernst, R.R. Coherence transfer by isotropic mixing-Application to proton correlation spectroscopy. J. Magn. Reson. 1983, 53, 521-528. [CrossRef]

54. McDougal, O.M.; Turner, M.W.; Ormond, A.J.; Poulter, C.D. Three-dimensional structure of conotoxin tx3a: An m-1 branch peptide of the M-superfamily. Biochemistry 2008, 47, 2826-2832. [CrossRef] [PubMed]

55. Vranken, W.F.; Boucher, W.; Stevens, T.J.; Fogh, R.H.; Pajon, A.; Llinas, P.; Ulrich, E.L.; Markley, J.L.; Ionides, J.; Laue, E.D. The CCPN data model for NMR spectroscopy: Development of a software pipeline. Proteins Struct. Funct. Bioinform. 2005, 59, 687-696. [CrossRef] [PubMed]

56. Vriend, G. WHAT IF-A molecular modeling and drug design program. J. Mol. Graph. 1990, 8, 52-56. [CrossRef]

57. Laskowski, R.A.; Rullmann, J.A.C.; MacArthur, M.W.; Kaptein, R.; Thornton, J.M. AQUA and PROCHECK-NMR: Programs for checking the quality of protein structures solved by NMR. J. Biomol. Nmr 1996, 8, 477-486. [CrossRef]

58. Eisenberg, D.; Luthy, R.; Bowie, J.U. VERIFY3D: Assessment of protein models with three-dimensional profiles. Macromol. Crystallogr. Pt B 1997, 277, 396-404. [CrossRef]

59. Chen, V.B.; Arendall, W.B.; Headd, J.J.; Keedy, D.A.; Immormino, R.M.; Kapral, G.J.; Murray, L.W.; Richardson, J.S.; Richardson, D.C. MolProbity: All-atom structure validation for macromolecular crystallography. Acta Crystallogr. Sect. D-Struct. Biol. 2010, 66, 12-21. [CrossRef] 
60. Sambasivarao, S.V.; Roberts, J.; Bharadwaj, V.S.; Slingsby, J.G.; Rohleder, C.; Mallory, C.; Groome, J.R.; McDougal, O.M.; Maupin, C.M. Acetylcholine Promotes Binding of alpha-Conotoxin MII at alpha(3)beta(2) Nicotinic Acetylcholine Receptors. Chembiochem 2014, 15, 413-424. [CrossRef]

61. Duan, Y.; Wu, C.; Chowdhury, S.; Lee, M.C.; Xiong, G.M.; Zhang, W.; Yang, R.; Cieplak, P.; Luo, R.; Lee, T.; et al. A point-charge force field for molecular mechanics simulations of proteins based on condensed-phase quantum mechanical calculations. J. Comput. Chem. 2003, 24, 1999-2012. [CrossRef]

62. Van der Spoel, D.; Lindahl, E.; Hess, B.; Groenhof, G.; Mark, A.E.; Berendsen, H.J.C. GROMACS: Fast, flexible, and free. J. Comput. Chem. 2005, 26, 1701-1718. [CrossRef]

(C) 2019 by the authors. Licensee MDPI, Basel, Switzerland. This article is an open access article distributed under the terms and conditions of the Creative Commons Attribution (CC BY) license (http://creativecommons.org/licenses/by/4.0/). 